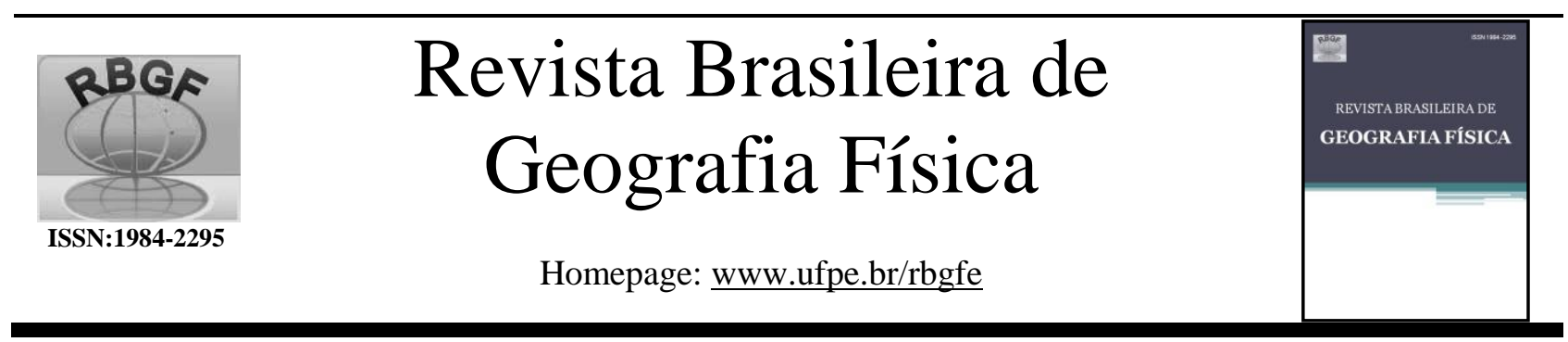

\title{
Análise temporal das condições meteorológicas e concentração de Material Particulado (MP10) na Região Metropolitana de São Paulo - SP
}

Madson Tavares Silva ${ }^{1}$, Carlos Antonio Costa dos Santos ${ }^{2}$, Marcos Renato Basílio Amorim $^{3}$, Bruce Kelly da Nóbrega Silva ${ }^{4}$, Jullianna Vitorio Vieira de Azevedo ${ }^{5}$, Eduardo da Silva Margalho ${ }^{6}$

${ }^{1}$ Dr. Meteorologia, Professor Adjunto; Unidade Acadêmica de Ciências Atmosféricas; Universidade Federal de Campina Grande - UFCG, Campina Grande-PB, Brasil. E-mail: madson.tavares@ufcg.edu.br (autor correspondente). ${ }^{2}$ Professor Adjunto; Unidade Acadêmica de Ciências Atmosféricas; Universidade Federal de Campina Grande - UFCG, Campina Grande-PB, Brasil. ${ }^{3}$ Unidade Acadêmica de Ciências Atmosféricas; Universidade Federal de Campina Grande - UFCG, Campina Grande-PB, Brasil. ${ }^{4}$ Bolsista de Pós-Doutorado; Departamento de Ciências Atmosféricas e Climáticas; Universidade Federal do Rio Grande do Norte, Natal-RN, Brasil. ${ }^{5}$ Doutoranda em Recursos Naturais; Universidade Federal de Campina Grande UFCG, Campina Grande-PB, Brasil, ${ }^{6}$ Mestrando em Meteorologia; Universidade Federal de Campina Grande - UFCG, Campina Grande-PB, Brasil.

Artigo recebido em 25/04/2018 e aceito em 12/10/2018

\section{R E S U M O}

Neste trabalho, a qualidade do ar na região de Interlagos e Ponte dos remédios é definida em termos da concentração do material particulado com diâmetro menor que $10 \mu \mathrm{m}\left(\mathrm{MP}_{10}\right)$. A concentração do $\mathrm{MP}_{10}$ no ar é resultado final de processos complexos, oriundos de vários fatores, que compreendem não só a emissão pelas fontes, bem como suas interações físicas (dispersão) e químicas (reações). A variabilidade da dispersão está diretamente ligada com a topografia e as condições meteorológicas. Diante desse contexto, o objetivo deste trabalho foi analisar a relação entre variáveis meteorológicas (VV, UR, T e P) e a concentração de $\mathrm{MP}_{10}$ nos meses extremos de 2014 (maior e menor concentração) utilizando o modelo de regressão linear múltipla. Os resultados mostraram que a concentração de $\mathrm{MP}_{10}$ está correlacionada com a VV e UR nas duas localidades em análise. Ademais, a maior parte dos dias desfavoráveis à dispersão do $\mathrm{MP}_{10}$ em 2014 ocorreu nos meses de junho e agosto. Meses do qual incidiram as maiores concentrações do MP 10 nas duas localidades.

Palavras-chave: $\mathrm{MP}_{10}$, variáveis meteorológicas, regressão linear múltipla.

\section{Temporal analysis of the meteorological conditions and concentration of Particulate Matter (PM10) in the Metropolitan Region of São Paulo - SP}

\begin{abstract}
A B S T R A C T
In this work, the air quality in the Interlagos and Ponte dos Remédios region is defined in terms of particulate matter concentration with a diameter smaller than $10 \mu \mathrm{m}\left(\mathrm{PM}_{10}\right)$. The $\mathrm{PM}_{10}$ concentration in the air is the final result of complex processes, which are due to several factors, that include not only the emission by the sources, but also their physical (dispersion) and chemical interactions (reactions). The variability of dispersion is directly connected to topography and weather conditions. In this context, the objective of this work was to analyze the relationship between meteorological variables (wind speed, relative humidity, temperature and precipitation.) and $\mathrm{PM}_{10}$ concentration in the extreme months of 2014 (highest and lowest concentrations) using the multiple linear regression model. The results showed that the $\mathrm{MP}_{10}$ concentration is correlated with the wind speed and relative humidity in the two localities under analysis. In addition, most of the unfavorable days to the $\mathrm{PM}_{10}$ dispersion in 2014 occurred in June and August. Months that focused the highest concentrations of $\mathrm{PM}_{10}$ in the two localities.
\end{abstract}

Keywords: $\mathrm{PM}_{10}$, meteorological variables, multiple linear regression.

\footnotetext{
* E-mail para correspondência:

madson.tavares@ufcg.edu.br (Silva, M. T.).
}

\section{Introdução}


O rápido desenvolvimento econômico e a crescente urbanização tornou a poluição do ar uma questão importante e oportuna em grandes cidades do mundo fazendo com que as mesmas experimentem em determinadas épocas do ano neblina ou neblina severa e persistente poluição, que compreende principalmente altos níveis de partículas finas $\left(\mathrm{PM}_{2.5}\right)$ e ozônio $\left(\mathrm{O}_{3}\right)$.

A poluição afeta negativamente a saúde (An et al., 2015) e ameaça o desenvolvimento sustentável da economia e da sociedade. Infelizmente, os níveis de poluentes em alguns dias do ano são muito mais altos do que os valores recomendados pela Organização Mundial da Saúde (Chai et al., 2014). A exposição à poluição do ar ambiente tem sido associada a aumento dos riscos de mortalidade e morbidade em todo o mundo (Zhang et al., 2014; Zhou et al., 2014; Chen et al., 2016; Guan et al., 2016; West et al., 2016; Song et al., 2017).

Segundo o projeto Global Burden of Diseases (GBD), a poluição do ar foi responsável por 1,6 milhão de mortes na China e 4,2 milhões mortes em todo o mundo em 2015 (Forouzanfar et al., 2016; Landrigan, 2016). Varias pesquisas ressaltam (Chen et al., 2013; Guo et al., 2014; Huang et al., 2014; Sun et al. 2014; Zhang et al., 2015: Guan et al., 2016; Li et al., 2016; Wang et al., 2016) que a poluição do ar severa e persistente resulta num grande impacto negativo sobre as condições de vida das populações que vivem em grandes regiões urbanas.

Problemas de poluição do ar atraem atenção especial do governo, da sociedade civil e dos pesquisadores. A poluição atmosférica severa está intimamente relacionada a um grande número fontes de emissão e alta intensidade de emissões, desfavoráveis condições meteorológicas, terreno especial, transporte de poluentes e conversão química na atmosfera (Crippa et al., 2013; He et al., 2013; Wang et al., 2014; Zhang et al., 2015; He et al., 2016; Liu et al. 2016).

As condições meteorológicas são os principais fatores que causam as variações do diaa-dia nas concentrações de poluentes (He et al., 2016). As condições de dispersão são determinadas por fenômenos climáticos de larga escala, bem como pela capacidade de depuração da atmosfera local. Pesquisas anteriores revelaram que tanto as emissões quanto as variações dominaram a tendência de concentração de poluentes a longo prazo (Wang et al., 2015). A causa principal da poluição atmosférica é que as emissões de poluentes excedem a capacidade ambiental atmosférica (An et al., 2015).

Segundo a Organização Mundial da Saúde - WHO (2006), um dos principais fatores que precisa ser levado em consideração quando se trata de poluição atmosférica, é a influência direita ou indireta das condições meteorológicas na dispersão dos poluentes. Devido a tal influência, é que alguns poluentes depois de emitidos, podem ser transportados a longas distâncias antes de alcançarem a superfície solo, ocasionando danos às populações mais distantes.

Dentre diversas condições meteorológicas, as mais importantes e que podem prognosticar níveis críticos de poluição do ar estão: a intensidade e direção dos ventos, inversão térmica e umidade relativa do ar (WHO, 2006).

De acordo com Seinfeld (1986) considerase poluente qualquer substância presente no ar em concentrações altas o suficiente para produzir efeitos mensuráveis e danosos em seres humanos, impróprio, nocivo, ofensivo à saúde, ao bem-estar, a flora, a fauna, e aos materiais. Os principais poluentes que podem estar presentes na atmosfera são: monóxido de carbono ( $\mathrm{CO}$ ), dióxido de carbono $\left(\mathrm{CO}_{2}\right)$, óxidos de enxofre (SOx), óxidos de nitrogênio (NOx), ozônio $\left(\mathrm{O}_{3}\right), \quad\left(\mathrm{MP}_{10}\right)$, hidrocarbonetos gasosos e outros compostos voláteis em menor concentração.

Os poluentes podem ser classificados em dois grupos: os emitidos diretamente pelas fontes de emissão, conhecidos como poluentes primários; e por fim, os que são originados através de reações fotoquímicas dos poluentes primários, conhecidos como poluentes secundários. O Conselho Nacional do Meio Ambiente (CONAMA, 1990) estabelece padrões nacionais de qualidade do ar, através da Resolução n. 3 de 28/6/1990. Ele define os padrões primários de qualidade do ar, que poderão afetar a saúde da população se ultrapassados e os padrões secundários de qualidade do ar, em que se prevê o mínimo efeito adverso sobre o bem-estar da população e ao meio ambiente. Para o material particulado $\left(\mathrm{MP}_{10}\right)$, estes padrões são de $150 \mu \mathrm{g} . \mathrm{m}^{-}$ ${ }^{3}$, primários e secundários, (não devendo ser ultrapassado mais que uma vez por ano) para o tempo de amostragem de $24 \mathrm{~h}$, e para a média aritmética anual eles são de $50 \mu \mathrm{g} \cdot \mathrm{m}^{-3}$. Segundo CONAMA as partículas suspensas no ar (MP) são originárias de ambas as fontes antropogênicas (por exemplo, veículos automotores, instalações industriais, lareiras residenciais) e fontes naturais (por exemplo, emissões biogênicas, poeira e maresia). A composição do MP aerotransportado pode ser orgânica, inorgânica ou uma mistura de ambos. Entre os diferentes elementos inorgânicos e substâncias que constituem a composição química do MP, os metais pesados associados ao MP respirável são de grande preocupação e, portanto, suas concentrações no ar ambiente devem ser consideradas e avaliadas. Estimativas das 
concentrações e valores extremos de $\mathrm{MP}_{10}$ permitem avaliar os padrões de qualidade do ar e possíveis ações de proteção à população, particularmente em eventos extremos.

Modelos estatísticos (regressão linear múltipla, redes neurais, entre outros) para estimativa da concentração diária de poluentes atmosféricos são amplamente utilizados por agências de monitoramento da qualidade do ar pela sua praticidade e acurácia (Stadlober et al., 2008). Estes modelos relacionam as condições meteorológicas e fontes de poluição com as concentrações dos poluentes e proporcionam estimativas satisfatórias com número reduzido de variáveis de entrada (Comrie et al., 1999). A aplicação de modelos lineares permite também avaliar a relação dos elementos meteorológicos com as condições de qualidade do ar (Chaloulakou et al., 2003).

A regressão linear múltipla é uma técnica de análise de dados amplamente utilizada para analisar uma variável dependente relacionada com duas ou mais variáveis independentes. O objetivo desta é prever as mudanças na variável dependente como resposta a mudanças nas variáveis independentes (Hair JR. et al., 2009).

O presente trabalho tem como objetivo avaliar temporalmente as características da qualidade do ar nas estações de monitoramento de Interlagos e Ponte dos Remédios no ano de 2014, inseridas na Região Metropolitana de São Paulo (RMSP), a partir da determinação dos meses de concentrações extremas (maior e menor concentração) do $\mathrm{MP}_{10}$. Bem como determinar o grau de correlação entre a variação da concentração do $\mathrm{MP}_{10}$ com as variáveis meteorológicas: velocidade do vento, umidade relativa, temperatura e precipitação pluvial, utilizando o modelo de regressão linear múltipla.
A área de estudo está situada na área de influência em duas estações automáticas da CETESB de monitoramento da qualidade do ar (Interlagos e Ponte dos Remédios) na RMSP no ano de 2014.

A primeira estação se localiza em Interlagos, na cidade de São Paulo, localizada na Rua Domingas Galleteri Blotta 171, Jardim Santa Cruz, Hospital Geral Pedreira (Figura 1). A topografia da região é plana, com caraterística de vale contendo 793 metros de altitude. O poluente monitorado na estação é o $\mathrm{MP}_{10} \mathrm{e}$ o tráfego da via mais próxima não impacta diretamente os valores de concentrações monitorados na estação, por se tratar de uma zona de adensamento de baixo residencial; bem como na região em torno, não estão localizadas fontes fixas de emissões (CETESB, 2014).

A segunda estação de monitoramento do $\mathrm{MP}_{10}$ está localizada na Ponte dos Remédios, Av. Embaixador Macedo Soares, 12889 Vila Leopoldina, no Centro de Treinamento do Gabinete do Comando de Policiamento Rodoviário (Figura 1). A topografia é caracterizada como plana, característica de vale, com uma altitude de 726 metros em relação ao nível do mar.

A via automotiva mais próxima da estação é a Marginal Tietê a 13 metros. O tráfego desta via impacta diretamente nos valores de concentrações monitorados na estação. Na região da estação de monitoramento não existem fontes fixas de emissões atmosféricas. A área de representatividade para o $\mathrm{MP}_{10}$ é considerada de microescala. (CETESB, 2014)

De acordo com a sua localização geográfica, a RMSP possui características particulares em seu clima, com um sistema meteorológico de características tropicais e extratropicais. Com sistemas meteorológicos de várias escalas de tempo e espaço que atingem a região, como, Frentes Frias, Linhas de Instabilidades e Zona de Convergência do Atlântico Sul (Coelho, 2007).

\section{Material e métodos}




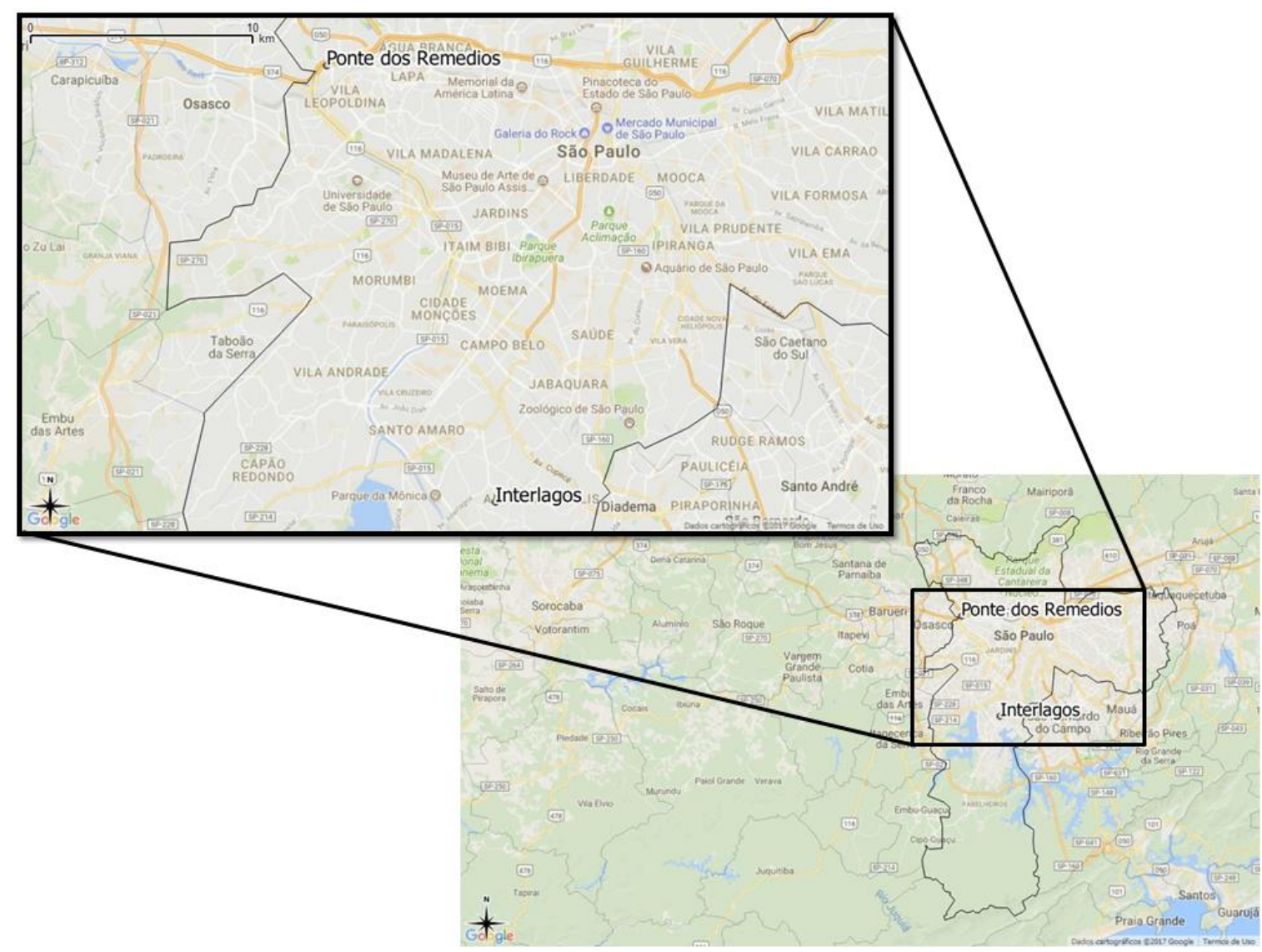

Figura 1. Localização das Estações Automáticas de Monitoramento da Qualidade do Ar utilizadas nesse estudo. Fonte: (Autores, 2017)

Dados meteorológicos e qualidade do ar

As concentrações de $\mathrm{MP}_{10}$, em dados de médias diárias para o ano de 2014, foram obtidas pela Companhia Ambiental do Estado de São Paulo (CETESB). As medidas de $\mathrm{MP}_{10}$ foram feitas nas Estações de Monitoramento da Qualidade do Ar, em Interlagos e na Ponte dos Remédios (Marginal do Rio Tietê).

As concentrações de $\mathrm{MP}_{10}$ foram determinadas nas estações de monitoramento pelo método da atenuação mássica da Radiação Beta (BA 1020, METONE, Grants Pass, OR), método padrão da agência de proteção ambiental norteamericana (EPA- Environmental Protection Agency) e também aceito pelo CONAMA. Estão contidos nos dados, médias diárias de concentração do $\mathrm{MP}_{10}$ (CETESB, 2014).

Os dados meteorológicos de médias diárias foram obtidos também junto a CETESB, no mesmo período das medidas do $\mathrm{MP}_{10}$ nas duas Estações. Foram quantificadas as seguintes variáveis meteorológicas: velocidade do vento (VV), temperatura média do ar (T), umidade relativa do ar (UR) e precipitação pluvial (P).
Análise estatística

A análise foi realizada no modo temporal para as duas Estações de Monitoramento da Qualidade do Ar, com o objetivo de associar as condições meteorológicas e concentração do $\mathrm{MP}_{10}$.

Para o estudo da relação entre a variável resposta $\left(\mathrm{MP}_{10}\right)$ e as variáveis explanatórias $(\mathrm{VV}$, $\mathrm{T}$, UR e P) foram utilizadas as seguintes metodologias estatísticas: correlação linear (verificar correlações entre as variáveis) e regressão linear múltipla (como o objetivo de criar um cenário que indique quais as variáveis meteorológicas se relacionam com a concentração de $\mathrm{MP}_{10}$ ) a fim de se estimar o diagnóstico de condição no momento. A regressão linear múltipla foi desenvolvida a partir do seguinte modelo proposto pela Equação (1)

$$
\begin{gathered}
\mathrm{M} P_{10, i}=b_{0}+b_{1} V V_{i}+b_{2} T_{i}+b_{3} U R_{i}+ \\
b_{4} P_{i}+\varepsilon_{i}
\end{gathered}
$$

em que: $\mathrm{M} P_{10, i}, V V_{i}, T_{i}, U R_{i}$ e $P_{i}$ são os i-ésimos (i $=1,2, \ldots, \mathrm{n})$ valores observados das respectivas 
variáveis; $b_{0}, b_{1}, b_{2}, b_{3}$ e $b_{4}$ são coeficientes a serem estimados e $\varepsilon_{i}$ é o erro aleatório, suposto independente e com distribuição normal de média zero e variância constante.

\section{Resultados e discussão}

Para as concentrações de $\mathrm{MP}_{10}$, verificouse que a média anual não ultrapassou os padrões nacionais de qualidade do ar primários e secundários de $50 \mu \mathrm{g} \cdot \mathrm{m}^{-3}$, em nenhuma das duas estações. O valor máximo diário observado foi de 130,5 $\mu \mathrm{g} \cdot \mathrm{m}^{-3}$, na Estação de

Monitoramento da Ponte dos Remédios no mês de agosto. As concentrações de $\mathrm{MP}_{10}$, medidas diariamente também não ultrapassaram os padrões da qualidade do ar, primários e secundários de 150 $\mu \mathrm{g} . \mathrm{m}^{-3}$ (Tabela 1).

Tabela 1. Estatísticas descritivas para o $\mathrm{MP}_{10}$, nas Estações de Monitoramento CETESB, Interlagos e Ponte dos Remédios no ano de 2014.

\begin{tabular}{lccc}
$\begin{array}{c}\text { Estação de } \\
\text { Monitoramento }\end{array}$ & $\begin{array}{c}\text { Média anual } \\
\left(\mu \mathrm{g} \cdot \mathrm{m}^{-3}\right)\end{array}$ & $\begin{array}{c}\text { Desvio Padrão } \\
\left(\mu \mathrm{g} \cdot \mathrm{m}^{-3}\right)\end{array}$ & $\begin{array}{c}\text { Concentração Máxima diária } \\
\left(\mu \mathrm{g} \cdot \mathrm{m}^{-3}\right)\end{array}$ \\
\hline Interlagos & 31,3 & 6,8 & 89,3 \\
Ponte dos Remédios & 41,1 & 9,6 & 130,5 \\
\hline
\end{tabular}

Em relação às médias mensais, foi constatado que na Estação de Monitoramento de Interlagos o mês de dezembro obteve a menor média mensal na concentração de $\mathrm{MP}_{10}$, igual a 20,0 $\mu \mathrm{g} . \mathrm{m}^{-3}$; já no mês de junho foi identificada a maior média mensal na concentração do $\mathrm{MP}_{10}$, igual a $38,9 \mu \mathrm{g} \cdot \mathrm{m}^{-3}$.

$\mathrm{Na}$ estação da Ponte dos remédios, próxima a marginal do Rio Tietê, o mês de abril apresentou a menor média de concentração do $\mathrm{MP}_{10}$, igual a $28,2 \mu \mathrm{g} . \mathrm{m}^{-3}$.

Tabela 2. Médias das concentrações mensais do MP Ponte dos Remédios no ano de 2014.

\begin{tabular}{lcccccccccccc}
\hline $\begin{array}{l}\text { Estação de } \\
\text { Monitoramento }\end{array}$ & \multirow{2}{*}{ Fan } & Fev & Mar & Abr & Mai & Jun & Jul & Ago & Set & Out & Nov & Dez \\
\hline Interlagos & 37,8 & - & 27,8 & 23 & 36 & 38,9 & 35,4 & 37,1 & 29,7 & 35,3 & 23,4 & 20 \\
Ponte dos Remédios & 35,1 & 41,1 & 29,8 & 28,2 & 45,2 & 50,6 & 47,1 & 58,3 & 45 & 49 & 32 & 31,3 \\
\hline
\end{tabular}

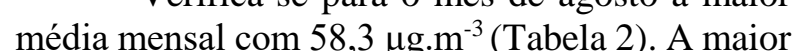
parte dos dias desfavoráveis à dispersão do $\mathrm{MP}_{10}$ em 2014 ocorreram nos meses de junho e agosto, em dias com ocorrência de alta porcentagem de calmaria e inversão térmica próxima à superfície (CETESB, 2014). Deste modo, se justifica a ocorrência dos meses de maiores concentrações do $\mathrm{MP}_{10}$ nas duas estações de monitoramento em junho (Interlagos) e agosto (Ponte dos Remédios).

o ano de 2014, a Estação de Interlagos apresentou 43 dias com concentrações de $\mathrm{MP}_{10}$ acima do limite de média diária recomendado, $50 \mu \mathrm{g} . \mathrm{m}^{-3}$.

Neste cenário é conveniente o estudo de Vahlsing e Smith (2012), uma revisão global sobre os padrões de qualidade de ar para $\mathrm{MP}_{10}$, através de questionários a 96 países, onde $84 \%$ representam a população no mundo, evidenciou que $72 \%$ deles possuíam padrão de medida diária para $\mathrm{MP}_{10}$. A média do valor do padrão encontrada entre os países foi $98 \mu \mathrm{g} \cdot \mathrm{m}^{-3}$, bem acima do preconizado pela OMS $\left(50 \mu \mathrm{g} \cdot \mathrm{m}^{-3}\right)$, porém abaixo do padrão 03 do CONAMA de $150 \mu \mathrm{g} \cdot \mathrm{m}^{-3}$. Além disso, o Brasil é tido como o penúltimo país a ter alterado o padrão, na década de 90, comparado aos outros países que vêm estabelecendo a atualização de seus padrões desde então. (Vahlsing e Smith, 2012). Para os padrões recomendados pela OMS, durante
Já a Estação da Ponte dos Remédios

apresentou 110 dias acima do limite. Neste cenário de dias com concentrações acima das recomendadas, são afetadas diretamente pessoas de grupos sensíveis (crianças, idosos e pessoas com doenças respiratórias e cardíacas) que podem apresentar sintomas como tosse seca e cansaço para concentrações até $80 \mu \mathrm{g} \cdot \mathrm{m}^{-3}$.

Dentre os 110 dias de médias acima das recomendações da OMS na Estação da Ponte dos Remédios, em 11 dias as concentrações médias de $\mathrm{MP}_{10}$ ultrapassaram o valor de $80 \mu \mathrm{g} \cdot \mathrm{m}^{-3}$, implicando problemas de saúde maiores para pessoas com doenças

respiratórias ou cardíacas. Idosos e crianças também tem os sintomas antigos agravados, bem como, observa-se um aumento de sintomas 
respiratórios na população em geral. (CETESB, 2014). A partir da Figura 2 é possível verificar o resultado da matriz de correlação entre as variáveis meteorológicas com as concentrações do $\mathrm{MP}_{10}$ na Estação de Monitoramento de Interlagos.

Todas as variáveis meteorológicas e as concentrações são relacionadas em pares para se constatar correlação ou não entre si. Quanto mais ajustada a reta diagonal, a relação das duas variáveis seguem uma tendência a normalidade linear. Neste caso os testes de normalidade das variáveis meteorológicas com o $\mathrm{MP}_{10}$ apresentaram grau de correlação para a VV, com o coeficiente de correlação igual a -0,7; da UR de -0,4 e também da $\mathrm{P}$ com o $\mathrm{MP}_{10}$ apresentando o mesmo valor de coeficiente.

Todavia ao nível de probabilidade de 5\%, apenas as correlações das variáveis independentes UR e VV em relação às concentrações do $\mathrm{MP}_{10}$ foram significativas, apresentando $\mathrm{p}$-valor muito abaixo de 0,05. Sugerindo que ambas tem grau de associação aceitável do ponto de vista estatístico.

A UR e VV apresentaram correlação negativa com as concentrações do $\mathrm{MP}_{10}$, ou seja, as funções apresentam coeficientes angulares negativos, sugerindo que quando maior seu valor menor a concentração do $\mathrm{MP}_{10}$.

A UR apresentou coeficiente de correlação de Spearman significativo $(0,3)$ em relação à $\mathrm{P}$, ou seja, a variabilidade da UR é indicador dos processos entre precipitação pluvial e a concentração do $\mathrm{MP}_{10}$. Essas relações sugerem correlação negativa entre UR e MP ${ }_{10}$, coerente com o sinal negativo do seu coeficiente ajustado pelo modelo linear.

O material particulado pode atuar como núcleo de condensação, influenciando no regime de precipitação pluvial local. Associada a propriedade do $\mathrm{MP}_{10}$ de atuar como núcleo de condensação, a UR pode se tornar indicador para a magnitude do processo de ressuspensão do solo (Vardoulakis e Kassomenos, 2008). Segundo a CETESB, estima-se que $25 \%$ das emissões do $\mathrm{MP}_{10}$ na região metropolitana de São Paulo é originária da ressuspensão desse material e outros $25 \%$ é proveniente da formação de aerossóis secundários na atmosfera.

Os dias considerados secos (úmidos) estão relacionados à baixa (alta) umidade, para esses dias há uma tendência de aumento (diminuição) da contribuição da ressuspensão do solo em relação ao particulado atmosférico, particularmente em dias com elevadas (baixas) VV (Vardoulakis e Kassomenos, 2008). No caso de baixos valores de UR, pode-se indicar que são períodos sem eventos de precipitação pluvial. Bem como, com o aumento da velocidade do vento espera-se maior taxa dispersão de $\mathrm{MP}_{10}$. 

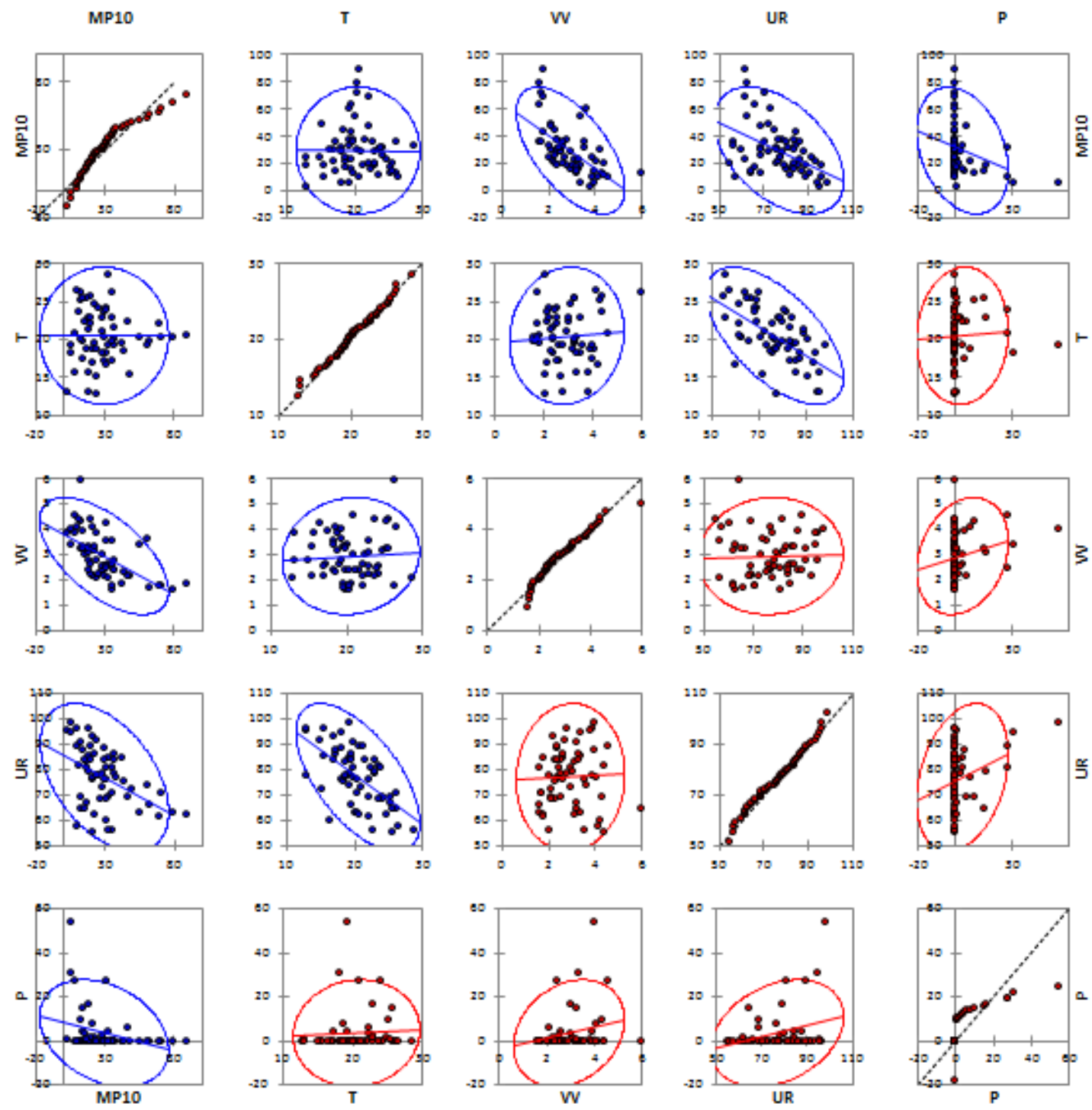

Figura 2. Matriz de correlação das variáveis meteorológicas em relação a concentração de $\mathrm{MP}_{10}$ na Estação de Monitoramento CETESB, Interlagos 2014.

Relacionando apenas a VV e UR com as médias diárias de concentrações de $\mathrm{MP}_{10}$ no mês de junho, observa-se que há uma tendência à concentração do $\mathrm{MP}_{10}$ quando a VV e UR diminuem. Em 10 dias as

concentrações do $\mathrm{MP}_{10}$ ultrapassaram os padrões recomendados pela OMS, implicando dias de nocividade à saúde da população desta região. Nota-se claramente que para os dias de maiores concentrações do $\mathrm{MP}_{10}$ as médias da VV e UR são as menores do mês (Figura 3).
Na RMSP, no início do outono, está presente o cenário de chuvas e calor. A partir de meados desta estação, a circulação atmosférica começa a mudar para a chegada do inverno (Coelho, 2007). No outono, as temperaturas começam a cair e a atmosfera fica com menor teor de umidade e, por isso, as chuvas diminuem. Nesta estação ocorrem os primeiros dias de inversão térmica. Com isso, os índices de poluição começam a aumentar na RMSP, piorando no período de inverno (Coelho, 2007). 


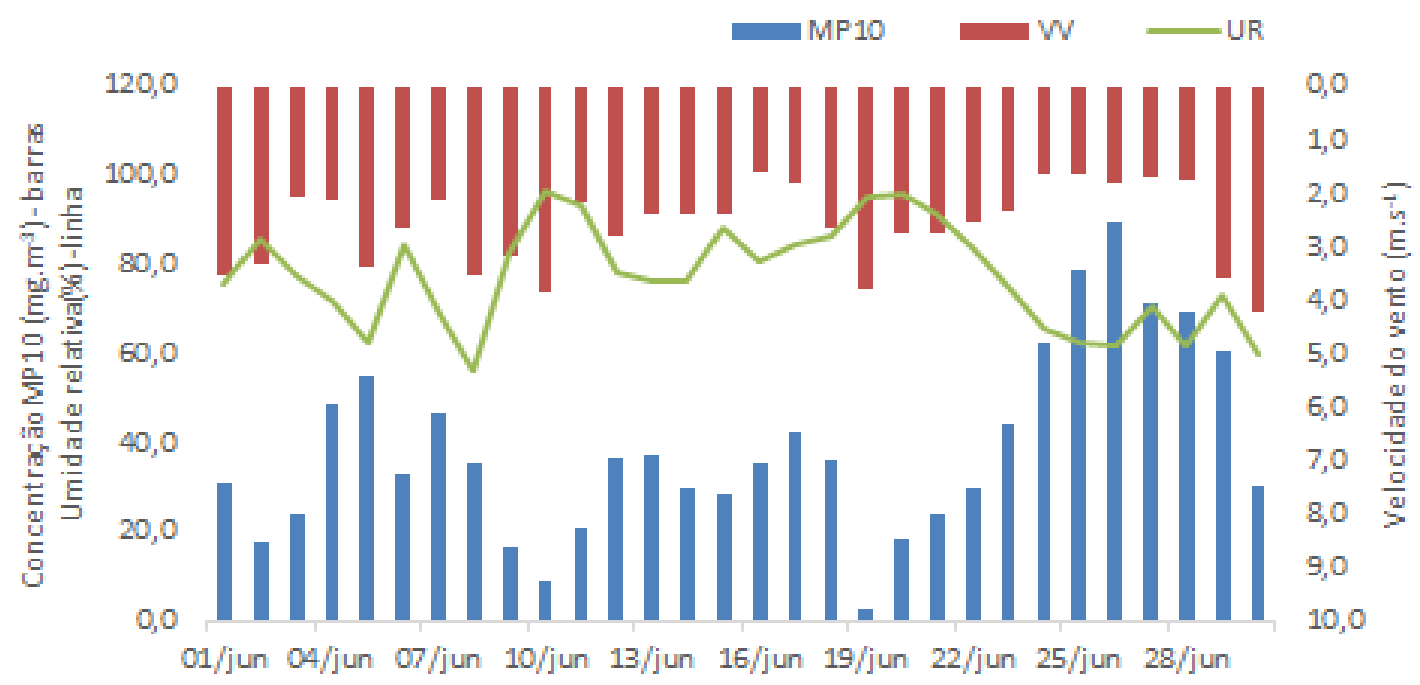

Figura 3. Médias diárias no mês de junho das concentrações de $\mathrm{MP}_{10}, \mathrm{VV}$ e UR na Estação de Monitoramento CETESB, Interlagos 2014.

Com a chegada a primavera, a atmosfera começa a ficar mais úmida e aquecida, dando início as primeiras chuvas que precedem o verão (Coelho, 2007). A VV tem picos de maiores variabilidades e a UR se mantém em altos teores no mês de dezembro, implicando em dias com menores concentrações do $\mathrm{MP}_{10}$ (Figura 4).
Nesta estação também começam a ocorrer altas temperaturas. Com a chegada do verão na segunda quinzena de dezembro, a atmosfera fica mais úmida e começa a chover com regularidade. Os poluentes de forma geral são removidos por deposição úmida (Coelho, 2007).

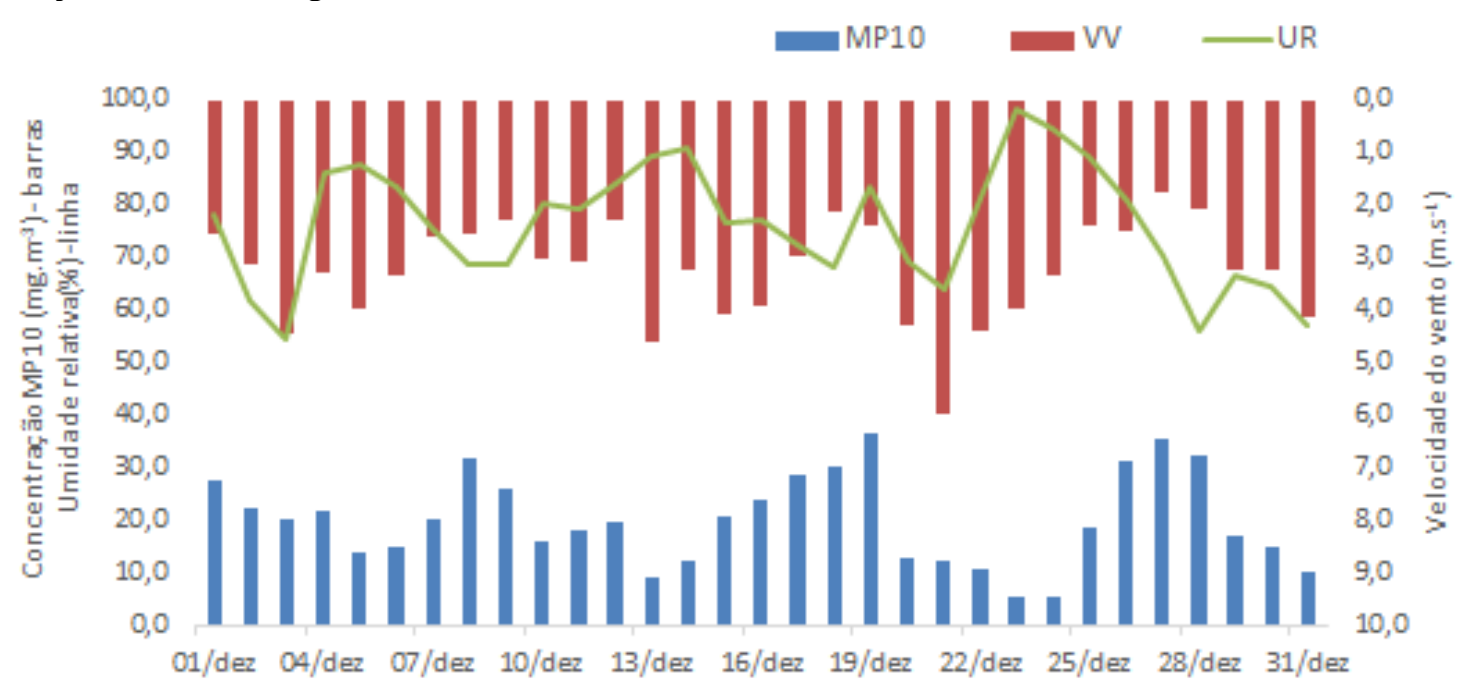

Figura 4. Médias diárias no mês de dezembro das concentrações de $\mathrm{MP}_{10}$, VV e UR na Estação de Monitoramento CETESB, Interlagos 2014.

Do ponto de vista estatístico, grande parte da composição do modelo é satisfeita apenas com intercepto VV e UR. Essas duas variáveis apresentaram um valor de $\mathrm{R}^{2}$ igual a 0,56 , ou seja, em conjunto essas variáveis explicam cerca de $56 \%$ da variabilidade das concentrações do $\mathrm{MP}_{10}$ na região Estação de Monitoramento de Interlagos em relação aos meses extremos do ano de 2014.

Para analisar o comportamento do $\mathrm{MP}_{10}$ com relação aos elementos meteorológicos, fez-se uma análise de regressão múltipla para as duas estações de monitoramento da CETESB nos meses que ambas apresentaram suas médias extremas de Silva, M. T.; Santos, C. A. C.; Amorim, M. R. B.; Silva, B. K. N.; Azevedo, J. V. V.; Margalho, E. S. mínimos e máximos mensais em relação à concentração do $\mathrm{MP}_{10}$. Ademais, se considerou as concentrações de $\mathrm{MP}_{10}$ como variável dependente e os elementos meteorológicos como variáveis independentes.

A partir da Tabela 3 é possível verificar o resultado do modelo de regressão linear múltipla. $\mathrm{O}$ intercepto é o ponto de partida do eixo $\mathrm{Y}$ da função $\left(b_{0}=117,9\right)$, ou seja, a reta não parte do ponto zero, sendo um coeficiente de valor numérico positivo, o intercepto da VV e UR é aditivo ao modelo. Através do coeficiente padronizado beta, pôde-se comparar o peso de cada 
coeficiente no modelo de regressão. Neste caso, a VV $\left(b_{1}=-11,9\right)$ apresenta maior poder de variação ao modelo em comparação a UR $\left(b_{2}=\right.$
$-0,7)$, todavia ambas apresentam relação negativa com a variável resposta $\left(\mathrm{MP}_{10}\right)$.

Tabela 3. Análise da regressão linear múltipla para as partículas inaláveis MP 10 na Estação de Monitoramento CETESB, Interlagos 2014.

\begin{tabular}{ccccc}
\hline Variáveis & Coeficientes & Erro Padrão & $\mathrm{t}$ & $\operatorname{Pr}>|\mathrm{t}|$ \\
\hline Intercepto & 117,9 & 11,7 & 10,0 & $<0,0001$ \\
VV & $-11,9$ & 1,7 & $-6,7$ & $<0,0001$ \\
UR & $-0,7$ & 0,1 & $-5,1$ & $<0,0001$ \\
\hline
\end{tabular}

Em posse dos valores dos coeficientes beta é obtida a equação de modelagem que relaciona a previsão da condição do material particulado a partir das estimativas das variáveis meteorológicas: $\mathrm{MP}_{10}=117,9-11,9 * \mathrm{VV}-0,7 * \mathrm{UR}$

A Figura 5 representa o ajuste do modelo para os meses de concentrações extremas do $\mathrm{MP}_{10}$ (junho e dezembro), onde praticamente $95 \%$ dos dados estão contidos no intervalo de confiança. $\mathrm{O}$ modelo também apresenta boa previsão para valores de $\mathrm{MP}_{10}$ abaixo de 80,0 $\mu \mathrm{g} . \mathrm{m}^{-3}$. Deste modo, o modelo é satisfatório no que diz respeito ao ajuste dos dados que foram observados e os que foram simulados, a fim de diagnosticar as condições do $\mathrm{MP}_{10}$ em relação às variáveis meteorológicas.

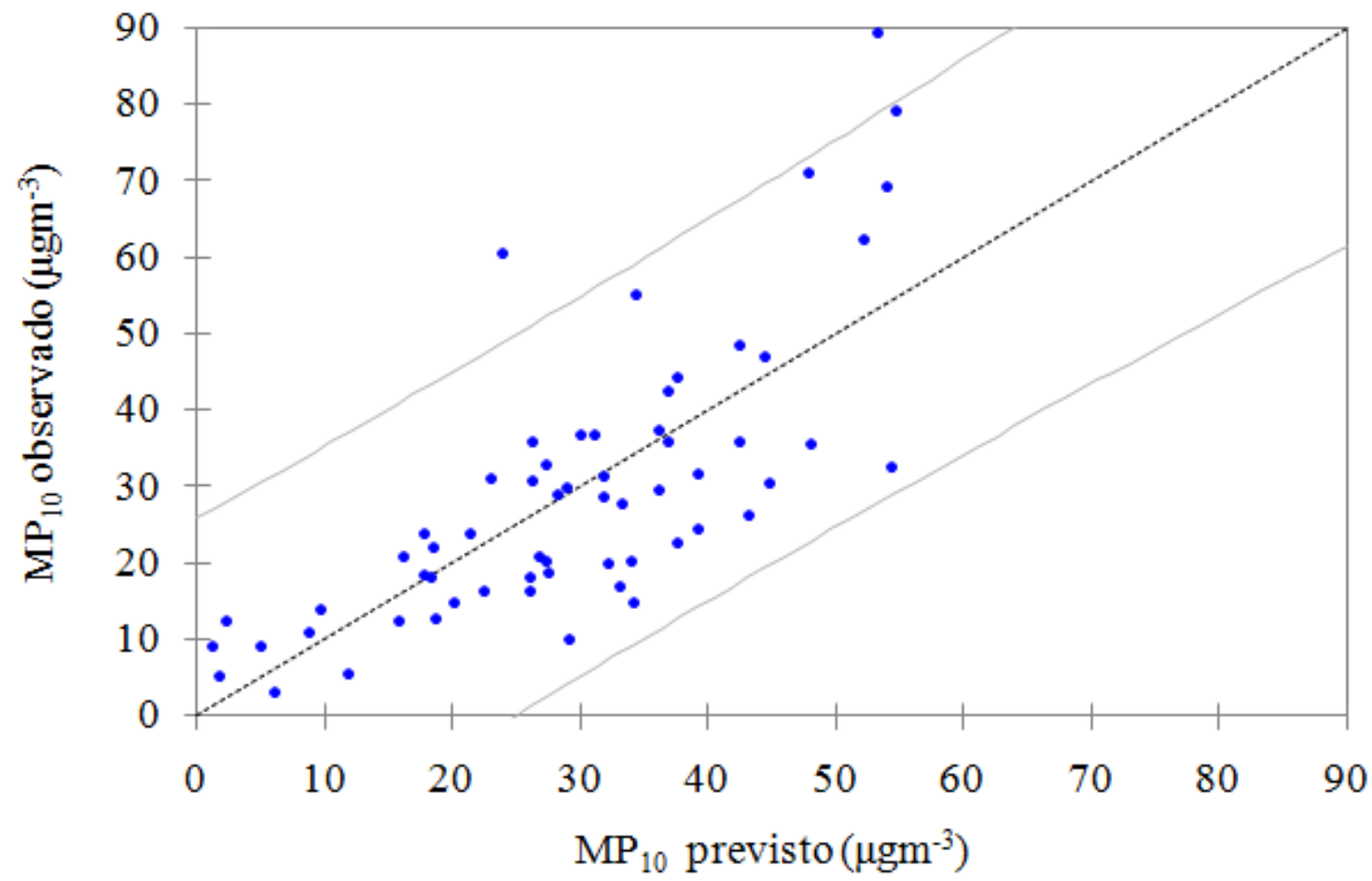

Figura 5. Modelo ajustado de Regressão Linear Múltipla do $\mathrm{MP}_{10}$ e variáveis meteorológicas na Estação de Monitoramento CETESB, Interlagos 2014.

O segundo ponto observacional (Estação de Monitoramento da Ponte dos Remédios) também apresentou correlação significativa entre VV e UR e as concentrações de $\mathrm{MP}_{10}$. Do ponto de vista estatístico, com o p-valor de ambas satisfaz a condição do valor aceitável $(<0,05)$; apresentando também relação de inversa proporcionalidade, explicada pelo coeficiente negativo de ambas as funções de correlação da VV e UR em relação ao $\mathrm{MP}_{10}$. As demais variáveis $\mathrm{T}$ e $\mathrm{P}$ apresentaram valores superiores ao p-valor aceitável, aferindo pouca ou nenhuma significância de correlação com as concentrações de $\mathrm{MP}_{10}$ (Figura 6). 

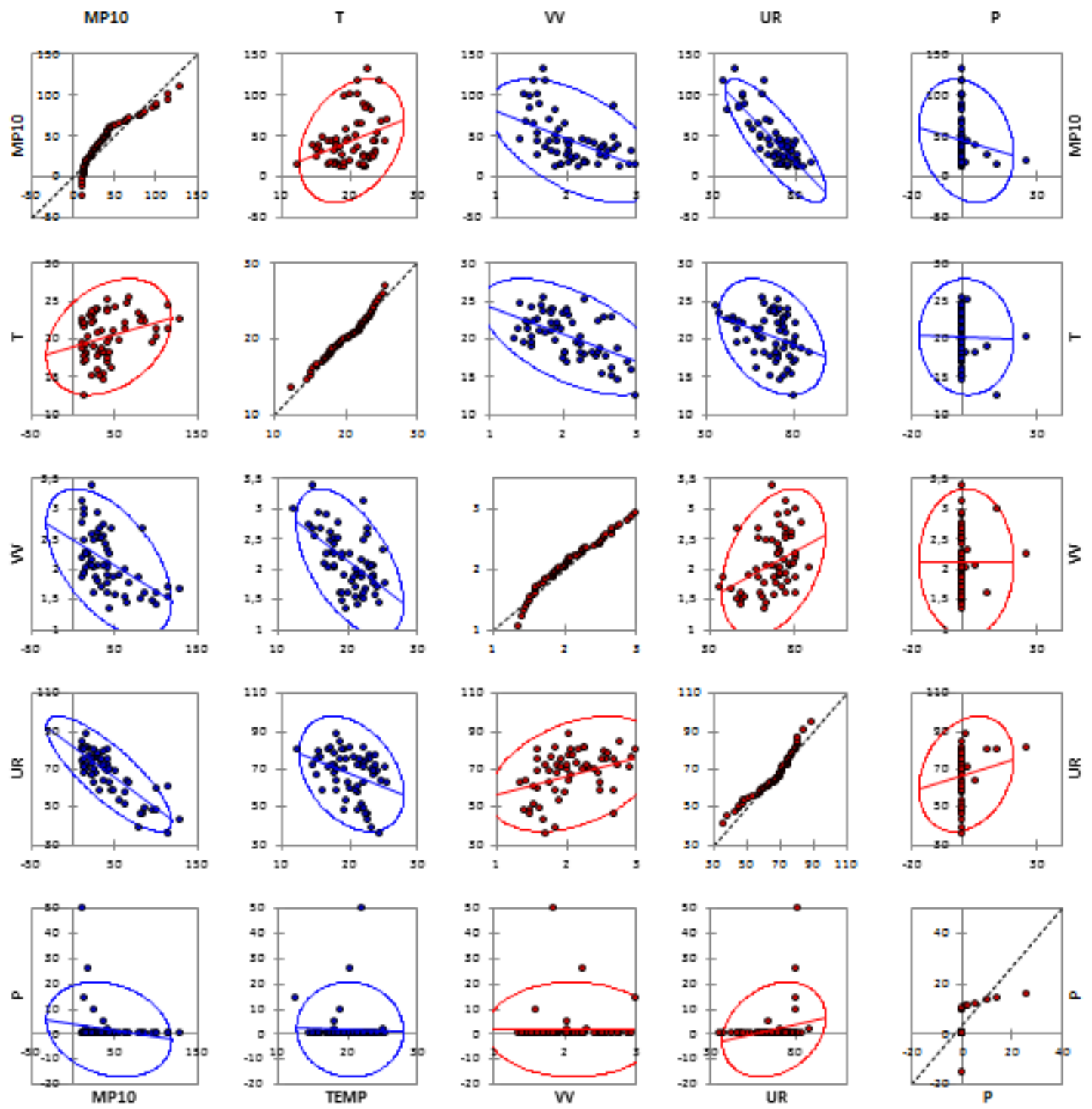

Figura 6. Matriz de correlação das variáveis meteorológicas em relação a concentração de $\mathrm{MP}_{10}$ na Estação de Monitoramento CETESB, Ponte dos Remédios 2014.

Em relação ao mês de menor concentração de $\mathrm{MP}_{10}$ (abril), observa-se uma tendência a dispersão do $\mathrm{MP}_{10}$ com o aumento da VV e UR, assim como ocorrido em Interlagos. Porém estando situada em uma zona urbana mais densa e com aproximadamente 13 metros da Marginal Tietê, a Estação da Ponte dos Remédios sofre com o impacto direto do tráfego automotivo em relação aos valores de concentrações monitorados. Deste modo, os valores das concentrações de $\mathrm{MP}_{10}$ mesmo no mês com menor média ultrapassaram em 4 dias o valor médio diário de concentração do $\mathrm{MP}_{10}$ recomendado pela OMS (Figura 7). 


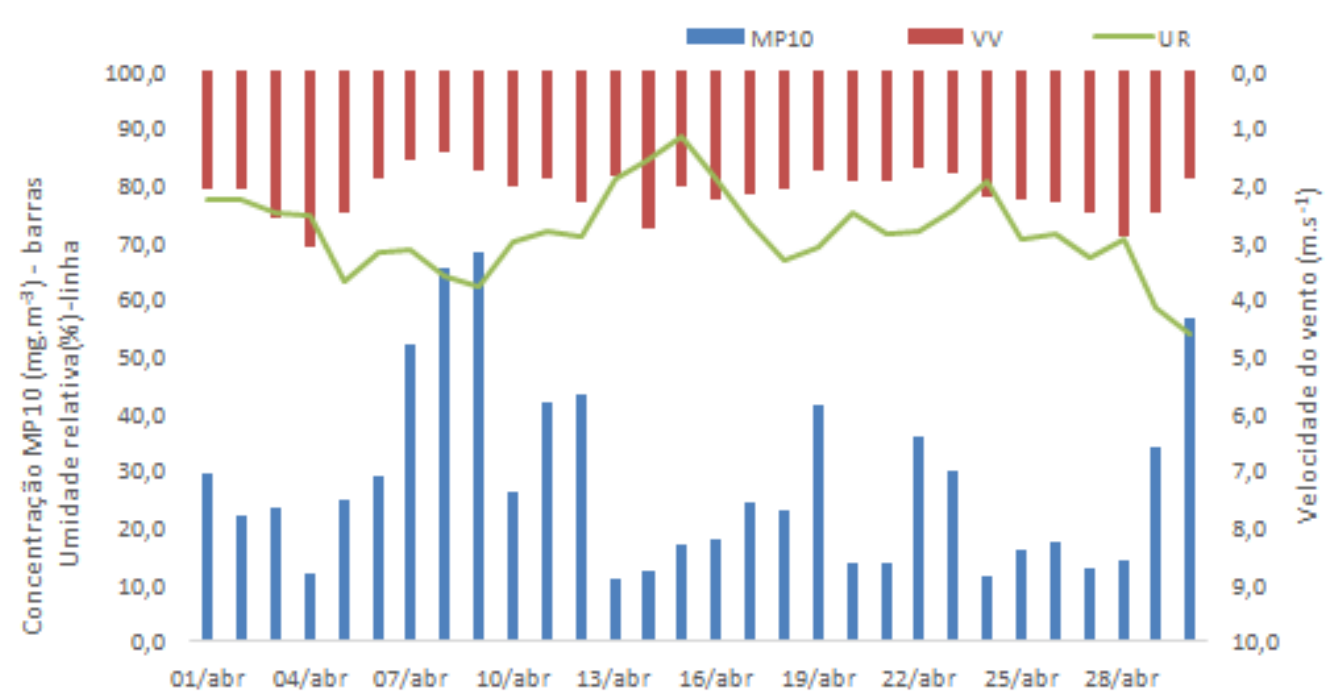

Figura 7. Médias diárias no mês de abril das concentrações de $\mathrm{MP}_{10}$, VV e UR na Estação de Monitoramento CETESB, Ponte dos Remédios 2014.

O mês de agosto se representou como o mês mais severo em relação as concentrações do $\mathrm{MP}_{10}$. Apresentando dias com UR baixas e VV variante a baixas intensidades, com concentrações do $\mathrm{MP}_{10}$ que ultrapassaram em 12 dias o valor recomendado pela OMS (Figura 8). Apesar da UR baixa, alguns dias com VV um pouco maiores que a média do mês, contribuiu para a dispersão do $\mathrm{MP}_{10}$. Um cenário descrito num ambiente com estabilidade atmosférica e pouca mistura vertical.

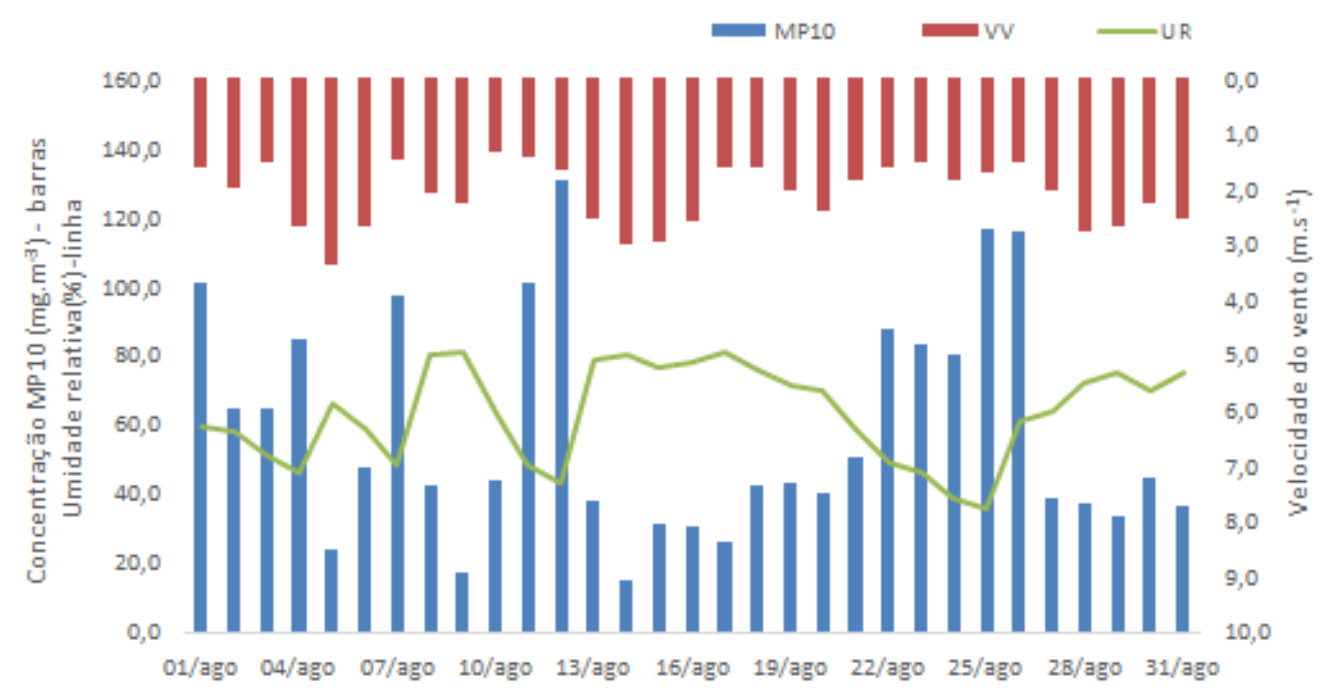

Figura 8. Médias diárias no mês de agosto das concentrações de $\mathrm{MP}_{10}$, VV e UR na Estação de Monitoramento CETESB, Ponte dos Remédios 2014.

De acordo com os resultados obtidos com o desenvolvimento do modelo de regressão linear múltipla, as variáveis VV e UR nesta estação apresentaram estatisticamente o valor de $\mathrm{R}^{2}$ igual a 0,7 , ou seja, VV e UR explicam aproximadamente $70 \%$ da variabilidade das concentrações do $\mathrm{MP}_{10}$ na região Estação de Monitoramento da Ponte dos Remédios.
A Tabela 4 expõe o resultado estatístico da regressão linear múltipla para o $\mathrm{MP}_{10}$ na estação da ponte dos remédios, assim como nos resultados da Estação de Interlagos, as variáveis VV e UR são redutivas, ou seja, seus coeficientes negativos tem representatividade de inversa proporcionalidade ao modelo. A variável $\mathrm{VV}$ apresenta maior contribuição ao modelo, verificada pelo seu coeficiente beta ser bem maior em módulo que o coeficiente da UR. 
Tabela 4. Análise da regressão linear múltipla para as partículas inaláveis $\mathrm{MP}_{10}$ na Estação de Monitoramento CETESB, Ponte dos Remédios 2014.

\begin{tabular}{ccccc}
\hline Variáveis & Coeficientes & Erro Padrão & $\mathrm{t}$ & $\operatorname{Pr}>|\mathrm{t}|$ \\
\hline Intercepto & 198 & 12,7 & 15,6 & $<0,0001$ \\
VV & $-16,1$ & 4,6 & $-3,5$ & $<0,0001$ \\
UR & $-1,8$ & 0,2 & $-9,7$ & $<0,0001$ \\
\hline
\end{tabular}

A equação obtida pelo modelo de regressão linear múltipla, que representa a correlação entre VV e UR em relação a condição do $\mathrm{MP}_{10}$ na Ponte dos Remédios é igual a: $\mathrm{MP}_{10}=198-16,1 * \mathrm{VV}$ $1,8^{*} \mathrm{UR}$

Assim como o ajuste do modelo estatístico na Estação de Interlagos, o resultado obtido para a
Estação da Ponte dos Remédios para as concentrações de $\mathrm{MP}_{10}$ nos meses extremos (abril e agosto) é similar na Figura 9. O modelo apresenta uma boa previsão para concentrações abaixo de $100 \mu \mathrm{g} . \mathrm{m}^{-3}$, bem como apresenta poucos pontos fora do intervalo de confiança do modelo.

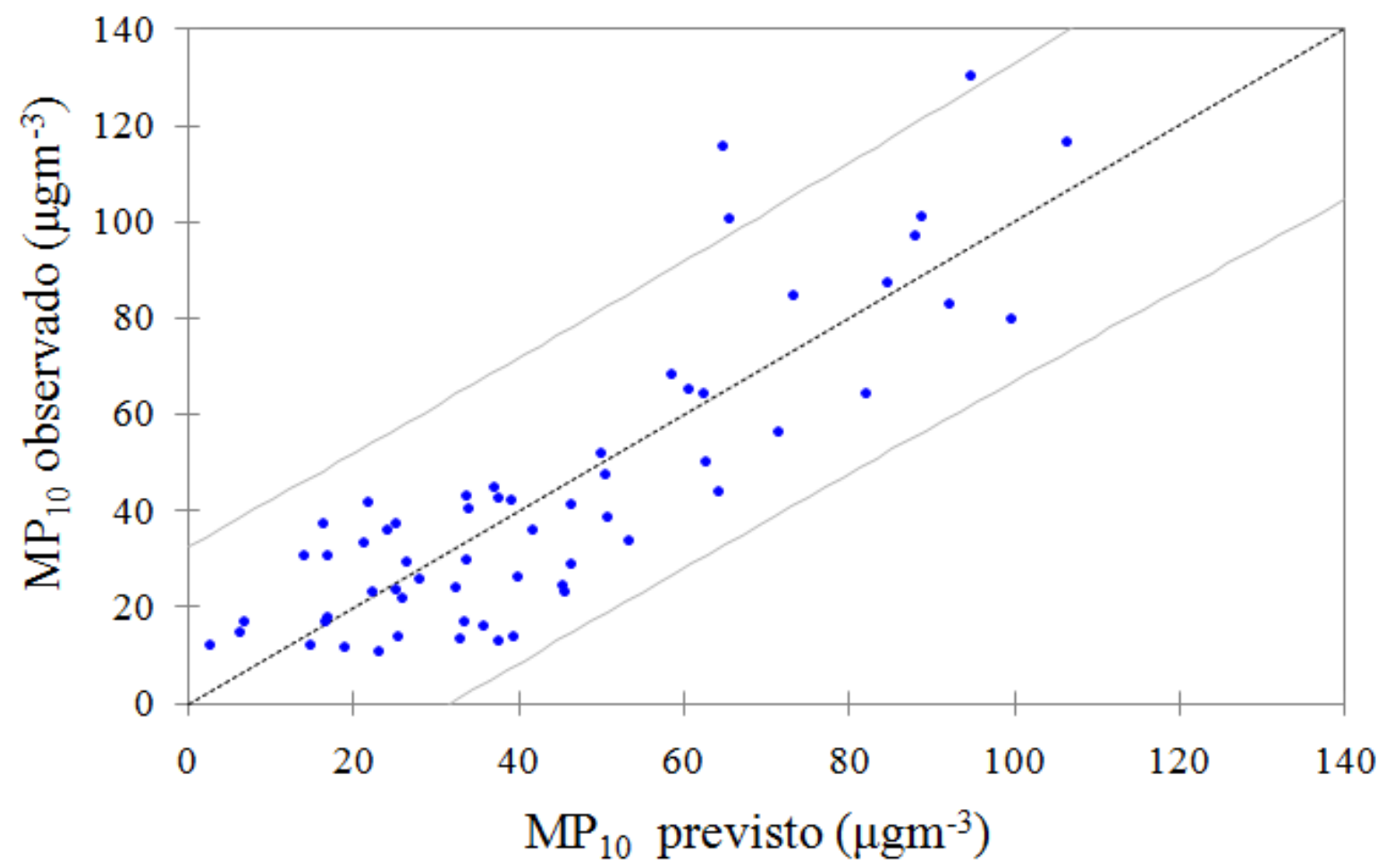

Figura 9. Modelo ajustado de Regressão Linear Múltipla do $\mathrm{MP}_{10}$ e variáveis meteorológicas na Estação de Monitoramento CETESB, Ponte dos Remédios 2014.

A presença dos resíduos nos dois modelos ajustados da regressão linear em Interlagos e na Ponte dos remédios, representados nas Figuras 5 e 9, podem ser explicados pela a ausência de componentes na modelagem tais como rugosidade da superfície, amplitude térmica, concentração de árvores, etc.

Segundo a CETESB, o período de maio a setembro é, geralmente, o mais desfavorável para a dispersão de poluentes primários na RMSP. O número de dias desfavoráveis à dispersão de poluentes no inverno de 2014 esteve abaixo da média dos últimos dez anos, com a ocorrência de
37 dias no período, que corresponde a $24 \%$ dos dias. Este percentual é semelhante aos invernos dos anos de 2009, 2012 e 2013, anos esses em que os totais das precipitações foram superiores à média climatológica, diferentemente do ano em análise, cujo inverno pode ser caracterizado como um dos mais secos dos últimos dez anos.

Entretanto, os seguintes parâmetros meteorológicos observados em 2014: maior ocorrência de dias com ventos mais intensos, menor número de dias com porcentagem de horas de calmaria superior a $25 \%$ e menor frequência de alturas de inversões térmicas abaixo de 200 metros, 
contribuíram para que as condições de dispersão durante o inverno de 2014, apesar da baixa precipitação pluviométrica, fossem mais favoráveis à dispersão de poluentes. (CETESB, 2014).

A RMSP possui variações sazonais significativas das condições atmosféricas, distinguindo-se nitidamente as condições

\section{Conclusões}

Em termos de previsão da qualidade do ar, o modelo mostrou resultados satisfatórios para as duas localidades nos meses de concentrações extremas do $\mathrm{MP}_{10}$, mas como todo modelo, ele apresenta suas limitações.

Dentre os elementos meteorológicos avaliados, a umidade relativa do ar e a velocidade dos ventos explicaram a maior parte da variabilidade da concentração de $\mathrm{MP}_{10}$ nas regiões das duas Estações de Monitoramento (Interlagos e Ponte dos Remédios) na cidade de São Paulo. Os elementos meteorológicos significativos apresentaram correlações inversamente proporcional à concentração do material particulado.

Foi possível constatar que, para os padrões nacionais de qualidade do ar estabelecidos pelo Conama, as concentrações do $\mathrm{MP}_{10}$ medidos diariamente e as médias aritméticas anuais, não ultrapassaram os padrões primários e secundários. Porem este não é fator decisivo para afirmar que os padrões de concentração do $\mathrm{MP}_{10}$ na região de estudo não são nocivos à saúde da população, pois para determinados momentos do ano de 2014 as regiões de Interlagos e principalmente da Ponte dos Remédios apresentaram padrões de concentrações de $\mathrm{MP}_{10}$ diários que apontam grau nocividade direta a saúde da população segundo as recomendações da OMS.

\section{Agradecimentos}

A CETESB pela disponibilidade dos dados meteorológicos e de qualidade do ar e ao Grupo de Pesquisa em Geotecnologias e modelagem de risco ambiental da Universidade Federal de Campina Grande - UFCG pelo apoio científico e tecnológico. Adicionalmente, o segundo autor agradece ao $\mathrm{CNPq}$ pela bolsa de Produtividade em Pesquisa.

\section{Referências}

An, X.Q., Tao, Y., Mi, S.Q., Sun, Z.B., Hou, Q., 2015. Association between PM10 and respiratory hospital admissions in different seasons in Lanzhou. J. Environ. Health 77, 64-71. climáticas de inverno e verão. As concentrações mais altas dos poluentes, à exceção do ozônio, ocorrem no período compreendido entre os meses de maio a setembro, devido à maior ocorrência de inversões térmicas em baixos níveis, alta porcentagem de calmaria, ventos fracos e baixos índices pluviométricos (CETESB, 2014).

CETESB - Companhia Ambiental do Estado de São Paulo. Série relatórios, Qualidade do Ar no Estado de São Paulo. 2014.

Chai, F., Gao, J., Chen, Z.,Wang, S., Zhang, Y., Zhang, J., Zhang, F., Yun, Y., Ren, C., 2014. Spatial and temporal variation of particulate matter and gaseous pollutants in 26 cities in China. J. Environ. Sci. 26, 75-82.

Chaloulakou, A., Grivas, G., Spyrellis, N., 2003 Neural network and multiple regression models for PM10 prediction in Athens: A comparative assessment. Journal of the Air e Waste Management Association 53, 11831190.

Chen, X., Zhang, L.W., Huang, J.J., Song, F.J., Zhang, L.P., Qian, Z.M., Trevathan, E.,Mao, H.J., Han, B., Vaughn, M., Chen, K.X., Liu, Y.M., Chen, J., Zhao, B.X., Jiang, G.H., Gu, Q., Bai, Z.P., Dong, G.H., Tang, N.J., 2016. Long-term exposure to urban air pollution and lung cancer mortality: a 12-year cohort study in Northern China. Sci. Total Environ. 571, 855-861.

Chen, Y., Ebenstein, A., Greenstone, M., Li, H., 2013. Evidence on the impact of sustained exposure to air pollution on life expectancy from China's Huai River policy. Proc. Natl. Acad. Sci. 110, 12936-12941.

Coelho, M., 2007. Uma Análise Estatística com vistas a Previsibilidade de Internações por Doenças Respiratórias em Função das Condições Meteorológicas na Cidade de São Paulo, Ano de obtenção. Tese (Doutorado). São Paulo, Universidade de São Paulo.

Comrie, A.C., Diem, J.E., 1999. Climatology and forecast modeling of ambient carbon monoxide in Phoenix, Arizona. Atmospheric Environment 33, 5023-5036.

CONAMA - Conselho Nacional do Meio Ambiente. Resolução 03 de Junho de 1990, $4^{\text {a }}$ ed. Brasília. 1992.

Correa, C.S., 1997. Estudo Micrometeorológico da Camada Limite Planetária Estável na Região de Porto Alegre. Dissertação (Mestrado). Porto Alegre, Universidade Federal do Rio Grande do Sul.

Crippa, M., Canonaco, F., Slowik, J.G., El Hadda, I., DeCarlo, P.F., Mohr, C., Heringa, M.F., 
Chirico, R., Marchand, N., TemimeRoussel, B., Abidi, E., Poulain, L., Wiedensohler, A., Baltensperger, U., Prevot, A.S.H., 2013. Primary and secondary organic aerosol origin by combined gasparticle phase source apportionment. Atmos. Chem. Phys. 13, 8411-8426.

Forouzanfar, M.H., Afshin, A., Alexander, L.T., Anderson, H.R., Bhutta, Z.A., 2016. Global, regional, and national comparative risk assessment of 79 behavioural, environmental and occupational, and metabolic risks or clusters of risks, $1990 \mathrm{e}$ 2015: a systematic analysis for the Global Burden of Disease Study 2015. Lancet 388, 1659-1724.

Guan, W.-J., Zheng, X.-Y., Chung, K.F., Zhong, N.-S., 2016. Impact of air pollution on the burden of chronic respiratory diseases in China: time for urgent action. Lancet 388, 1939-1951.

Guo, S., Hu, M., Zamora, M.L., Peng, J., Shang, D., Zheng, J., Du, Z., Wu, Z., Shao, M., Zeng, L., Molina, M.J., Zhang, R., 2014. Elucidating severe urban haze formation in China. Proc. Natl. Acad. Sci. 111, 1737317378.

Hair Jr., J.F., Black, W. C., Babin, B. J., Anderson, R. E., Tatham, R. L. Análise multivariada de dados. Porto Alegre: Bookman, 2009.

He, J.J., Yu, Y., Liu, N., Zhao, S.P., 2013. Numerical model-based relationship between meteorological conditions and air quality and its implication for urban air quality management. Int. J. Environ. Pollut. 53, 265-286.

He, J.J., Yu, Y., Xie, Y.C., Mao, H.J., Wu, L., Liu, N., Zhao, S.P., 2016. Numerical modelbased artificial neural network model and its application for quantifying impact factors of urban air quality. Water Air Soil Pollut. 227, 235.

Huang, R.J., Zhang, Y., Bozzetti, C., Ho, K.F., Cao, J.J., Han, Y., Daellenbach, K.R., Slowik, J.G., Platt, S.M., Canonaco, F., Zotter, P., Wolf, R., Pieber, S.M., Bruns, E.A., Crippa, M., Ciarelli, G., Piazzalunga, A., Schwikowski, M., Abbaszade, G., Schnelle-Kreis, J., Zimmermann, R., An, Z., Szidat, S., Baltensperger, U., El Haddad, I., Prevot, A.S., 2014. High secondary aerosol contribution to particulate pollution during haze events in China. Nature 514, 218-222.

Landrigan, P.J., 2016. Air Pollution and Health. The Lancet Public Health.

Li, S., Williams, G., Guo, Y., 2016. Health benefits from improved outdoor air qualityand intervention in China. Environ. Pollut. 214, 17-25.

Liu, B., Liang, D., Yang, J., Dai, Q., Bi, X., Feng, Y., Yuan, J., Xiao, Z., Zhang, Y., Xu, H., 2016. Characterization and source apportionment of volatile organic compounds based on 1-year of observational data in Tianjin, China. Environ. Pollut. 218, 757-769.

Seinfeld, J.H. Atmospheric Chemistry and Physics of Air Polution. Ed. John Wiley, New York. 1986. (Reprinted, 1998).

Song, C., He, J., Wu, L., Jin, T., Chen, X., Li, R., Ren, P., Zhang, L., Mao, H., 2017. Health burden attributable to ambient PM2.5 in China. Environ. Pollut. 223, 575-586.

Stadlober, E., Hormann, S., Pfeiler, B., 2008.Quality and performance of a PM10 daily forecasting model. Atmospheric Environment, v. 42, p. 1098-1109.

Sun, Y., Jiang, Q., Wang, Z., Fu, P., Li, J., Yang, T., Yin, Y., 2014. Investigation of the sources and evolution processes of severe haze pollution in Beijing in January 2013. J. Geophys. Res. Atmos. 119, 4380-4398.

Vahlsing, C., Smith. K.R., 2012. Global review of national ambient air quality standards for $\mathrm{MP}_{10}$ and $\mathrm{SO} 2$ (24h). Air Quality, Atmosphere e Health, v. 5, n. 4, p.393 - 399.

Vardoulakis, S., Kassomenos, P., 2008.Sources and factors affecting PM10 levels in two European cities: Implications for local air quality management. Atmospheric Environment, v. 42, p. 3949-3963.

Wang, G., Zhang, R., Gomez, M.E., Yang, L., Levy Zamora, M., Hu, M., Lin, Y., Peng, J., Guo, S., Meng, J., Li, J., Cheng, C., Hu, T., Ren, Y., Wang, Y., Gao, J., Cao, J., An, Z., Zhou, W., Li, G., Wang, J., Tian, P., Marrero-Ortiz, W., Secrest, J., Du, Z., Zheng, J., Shang, D., Zeng, L., Shao, M., Wang, W., Huang, Y., Wang, Y., Zhu, Y., Li, Y., Hu, J., Pan, B., Cai, L., Cheng, Y., Ji, Y., Zhang, F., Rosenfeld, D., Liss, P.S., Duce, R.A., Kolb, C.E., Molina, M.J., 2016. Persistent sulfate formation from London Fog to Chinese haze. Proc. Natl. Acad. Sci. U. S. A. 113, 13630-13635.

Wang, L.T., Wei, Z., Yang, J., Zhang, Y., Zhang, F.F., Su, J., Meng, C.C., Zhang, Q., 2014. The 2013 severe haze over southern Hebei, China: model evaluation, source apportionment, and policy implications. Atmos. Chem. Phys. 14, 3151-3171.

Wang, Y.Q., Zhang, X.Y., Sun, J.Y., Zhang, X.C., Che, H.Z., Li, Y., 2015. Spatial and temporal variations of the concentrations of $\mathrm{PM}_{10}$, 
$\mathrm{PM}_{2.5}$ and $\mathrm{PM}_{1}$ in China. Atmos. Chem. Phys. 15, 13585-13595.

West, J.J., Cohen, A., Dentener, F., Brunekreef, B., Zhu, T., Armstrong, B., Bell, M.L., Brauer, M., Carmichael, G., Costa, D.L., Dockery, D.W., Kleeman, M., Krzyzanowski, M., Kunzli, N., Liousse, C., Lung, S.C., Martin, R.V., Poschl, U., Pope 3rd, C.A., Roberts, J.M., Russell, A.G., Wiedinmyer, C., 2016. What we breathe impacts our health: improving understanding of the link between air pollution and health. Environ. Sci. Technol. 50, 4895-4904.

WHO - WORLD HEALTH ORGANIZATION. Air Quality Guidelines for Particulate Matter, Ozone, Nitrogen Dioxide and Sulphur Dioxide. Global update 2005. Summary of Risk Assessment. Geneva, 2006.
Zhang, L., Liu, L.C., Zhao, Y.H., Gong, S., Zhang, X.Y., Henze, D.K., Capps, S.L., Fu, T., Zhang, Q., Wang, Y.X., 2015. Source attribution of particulate matter pollution over North China with the adjoint method. Environ. Res. Lett. 10, 084011.

Zhang, L.W., Chen, X., Xue, X.D., Sun, M., Han, B., Li, C.P., Ma, J., Yu, H., Sun, Z.R., Zhao, L.J., Zhao, B.X., Liu, Y.M., Chen, J., Wang, P.P., Bai, Z.P., Tang, N.J., 2014. Long-term exposure to high particulate matter pollution and cardiovascular mortality: a 12-year cohort study in four cities in northern China. Environ. Int. 62, 41-47.

Zhou, M., Liu, Y., Wang, L., Kuang, X., Xu, X., Kan, H., 2014. Particulate air pollution and mortality in a cohort of Chinese men. Environ. Pollut. 186, 1-6. 